$\sqrt{6}$

EDITOR'S

CHOICE
${ }^{1}$ Leeds Gastroenterology Institute, Leeds General Infirmary, Great George Street, Leeds, UK

${ }^{2}$ Leeds Institute of Molecular Medicine, University of Leeds, Leeds, UK

\section{Correspondence to}

Dr Alex Ford, Leeds

Gastroenterology Institute,

Room 230, D Floor, Clarendon

Wing, Leeds General Infirmary,

Great George Street, Leeds,

LS1 3EX, UK

alexf12399@yahoo.com

Revised 1 October 2010

Accepted 26 October 2010

\title{
Effect of laxatives and pharmacological therapies in chronic idiopathic constipation: systematic review and meta-analysis
}

\author{
Alexander C Ford, ${ }^{1,2}$ Nicole C Suares ${ }^{1}$
}

\begin{abstract}
Background There has been no definitive systematic review and meta-analysis to date examining the effect of laxatives and pharmacological therapies in chronic idiopathic constipation (CIC).

Objective To assess efficacy of these therapies systematically in CIC.

Design Systematic review and meta-analysis of randomised controlled trials (RCTs).

Data sources MEDLINE, EMBASE, and the Cochrane central register of controlled trials were searched (up to September 2010).
\end{abstract}

Eligibility criteria for selecting studies Placebocontrolled trials of laxatives or pharmacological therapies in adult CIC patients were eligible. Minimum duration of therapy was 1 week. Trials had to report either a dichotomous assessment of overall response to therapy at last point of follow-up in the trial, or mean number of stools per week during therapy.

Study appraisal and synthesis methods Symptom data were pooled using a random effects model. Effect of laxatives or pharmacological therapies compared to placebo was reported as $\mathrm{RR}$ of failure to respond to therapy, or a weighted mean difference (WMD) in mean number of stools per week, with $95 \% \mathrm{Cls}$.

Results Twenty-one eligible RCTs were identified. Laxatives (seven RCTs, 1411 patients, $R R=0.52 ; 95 \% \mathrm{Cl}$ 0.46 to 0.60 ), prucalopride (seven trials, 2639 patients, $\mathrm{RR}=0.82 ; 95 \% \mathrm{Cl} 0.76$ to 0.88 ), lubiprostone (three RCTs, 610 patients, $\mathrm{RR}=0.67 ; 95 \% \mathrm{Cl} 0.56$ to 0.80 ), and linaclotide (three trials, 1582 patients, $\mathrm{RR}=0.84 ; 95 \% \mathrm{Cl}$ 0.80 to 0.87 ) were all superior to placebo in terms of a reduction in risk of failure with therapy. Treatment effect remained similar when only RCTs at low risk of bias were included in the analysis. Diarrhoea was significantly more common with all therapies.

Limitations Only two RCTs were conducted in primary care, and total adverse events data for laxatives and linaclotide were sparse.

Conclusions Laxatives, prucalopride, lubiprostone and linaclotide are all more effective than placebo for the treatment of CIC

\section{INTRODUCTION}

Chronic idiopathic constipation (CIC) is a functional disorder of the gastrointestinal tract, characterised by persistently difficult, infrequent, or incomplete defaecation, in the absence of any physiological abnormality. ${ }^{1}$ The condition is common, with a prevalence of between $4 \%$ and $20 \%$ in cross-sectional community-based surveys. ${ }^{2-6}$ Chronic idiopathic constipation is more common in females, those of lower socioeconomic status and

\section{Significance of this study}

What is already known about this subject?

- Chronic idiopathic constipation is a common functional disorder of the gastrointestinal tract.

- The condition is difficult to treat.

- Evidence for any benefit of laxatives is conflicting, and there has been no definitive summary of the evidence for efficacy of newer pharmacological agents.

What are the new findings?

- Polyethylene glycol, sodium picosulfate, bisacodyl, prucalopride, lubiprostone and linaclotide were all more effective than placebo for treating chronic idiopathic constipation, but data to support efficacy of lactulose were limited.

- Diarrhoea was significantly more common in patients assigned to both laxatives and pharmacological therapies.

How might it impact on clinical practice in the foreseeable future?

- Guidelines for the management of chronic idiopathic constipation should be updated to include this useful information.

lower educational level, and older individuals. ${ }^{2} 67$ Up to $20 \%$ of sufferers consult a physician with their symptoms, ${ }^{2}$ and the impact of CIC on quality of life for patients is comparable with that for organic conditions, such as chronic obstructive pulmonary disease, diabetes and depression. ${ }^{8}$

Traditionally, individuals with CIC are told to increase dietary fibre intake in order to alleviate symptoms, but there is little evidence from randomised controlled trials (RCTs) that this approach is of any benefit, even in the short-term treatment of the condition. ${ }^{9} 10$ In a recent multi-national survey of CIC patients, between $16 \%$ and $40 \%$ reported that they used laxatives, with almost twothirds using them on at least a monthly basis. ${ }^{6}$ However, levels of dissatisfaction with laxatives are high, primarily due to concerns about efficacy and safety. ${ }^{11}$ In addition, laxatives do not target the pathophysiological abnormalities that may contribute to the symptoms of CIC.

As a result, novel drug therapies for the disorder have been developed within the last 10 years Prucalopride is a selective agonist at the 5-hydroxytryptamine-4 (5- $\left.\mathrm{HT}_{4}\right)$ receptor, leading to increased colonic motility and transit. ${ }^{12}$ Lubiprostone and 
linaclotide are drugs that act on chloride channels and guanylate cyclase receptors in the intestinal enterocyte, respectively. Both of these agents increase the chloride concentration of intestinal fluid, thereby stimulating intestinal fluid secretion and accelerating transit. ${ }^{13} 14$

At present, management guidelines for CIC do not make any firm recommendations to support the use of laxatives or pharmacological therapies in the condition. ${ }^{15-17}$ Part of the explanation for this may be that there has been no recent definitive quantitative summary of all available evidence for their efficacy in CIC. We have therefore conducted a systematic review and meta-analysis of RCTs to examine this issue.

\section{METHODS}

\section{Search strategy and study selection}

A search of the medical literature was conducted using MEDLINE (1950 to September 2010), EMBASE and EMBASE Classic (1947 to September 2010), and the Cochrane central register of controlled trials (Issue 3, July 2010). Randomised placebo-controlled trials examining the effect of laxatives (osmotic or stimulant) or pharmacological therapies (prucalopride, lubiprostone or linaclotide) in adult patients ( $>90 \%$ of participants over the age of 16 years) with CIC were eligible for inclusion (box 1). The first period of cross-over RCTs were also eligible for inclusion. A diagnosis of CIC could be based on clinical symptoms, a physician's opinion, or the Rome I, II or III diagnostic criteria, ${ }^{1} 1819$ supplemented by negative investigations where trials deemed this necessary. Studies that recruited patients with organic constipation, drug-induced constipation, or highly selected groups of patients (such as elderly patients who were also institutionalised) were ineligible. Duration of treatment had to be at least 1 week. Trials using any dose of laxative or pharmacological therapy were considered eligible. Studies had to report either a dichotomous assessment of overall response to therapy at the last point of follow-up in the trial, or continuous data in the form of mean number of stools per week during therapy. First and senior authors of studies were contacted to provide additional information on trials where required.

Studies on CIC were identified with the terms: constipation or gastrointestinal transit (both as medical subject headings (MeSH) and free text terms), or functional constipation, idiopathic constipation, chronic constipation, or slow transit (as free text terms). These were combined using the set operator AND with studies identified with the terms: laxatives, cathartics, anthraquinones, phenolphthaleins, indoles, phenols, lactulose, polyethylene glycol,

\section{Box 1 Eligibility criteria}

- Randomised controlled trials

- Adults ( $>90 \%$ of participants aged $>16$ years)

- Diagnosis of CIC based on either clinical symptoms, a physician's opinion, or meeting specific diagnostic criteria*, supplemented by negative investigations where trials deemed this necessary.

- Compared osmotic laxatives, stimulant laxatives, prucalopride, lubiprostone or linaclotide with placebo.

- Minimum duration of therapy 7 days.

- Dichotomous assessment of overall response to therapy or mean number of stools per week during therapy.

* Rome I, II, or III criteria. senna plant, senna extract, bisacodyl, phosphates, dioctyl sulfosuccinic acid, magnesium, magnesium hydroxide, sorbitol, poloxamer, serotonin agonists, receptors, serotonin, $5-H_{4}$, or receptors, prostaglandin $E$ (both as MeSH terms and free text terms), or the following free text terms: sodium picosulphate, docusate, milk of magnesia, danthron, senna $\$$, poloxalkol, prucalopride, lubiprostone, or linaclotide.

There were no language restrictions. Abstracts of the papers identified by the initial search were evaluated independently by both investigators for appropriateness. All potentially relevant papers were obtained and evaluated in detail. Foreign language papers were translated. Abstract books of conference proceedings between 2002 and 2010 were hand-searched to identify potentially eligible studies published only in abstract form. Bibliographies of all identified relevant studies were used to perform a recursive search. Articles were assessed independently by two investigators using pre-designed eligibility forms, according to the pre-defined eligibility criteria. Disagreement between investigators was resolved by discussion.

\section{Outcome assessment}

The primary outcomes assessed were the efficacy of laxatives or pharmacological therapies compared with placebo in CIC, in terms of failure to respond to therapy, or effect on mean number of stools per week during treatment. Secondary outcomes included effect on individual symptoms of CIC, and adverse events occurring as a result of therapy (overall numbers, as well as individual adverse events such as nausea, vomiting, diarrhoea, abdominal pain, abdominal bloating, or headache).

\section{Data extraction}

All data were extracted independently by two investigators on to a Microsoft Excel spreadsheet (XP professional edition; Microsoft, Redmond, Washington, USA) as dichotomous outcomes (response or no response to therapy), or mean number of stools per week with a SD. In addition, the following clinical data were extracted for each trial, where available: setting (primary, secondary or tertiary care), number of centres, country of origin, dose and duration of therapy, concomitant medications allowed, criteria used to define CIC, primary outcome measure used to define response to therapy, method used to generate the randomisation schedule and conceal allocation, level of blinding, and proportion of female patients. Data were extracted as intention-to-treat analyses, with drop-outs assumed to be treatment failures (ie, no response to therapy), wherever trial reporting allowed. If this was not clear from the original article we performed an analysis on all patients with reported evaluable data.

\section{Assessment of risk of bias}

This was performed independently by two investigators, with disagreements resolved by discussion. Risk of bias was assessed as described in the Cochrane handbook, ${ }^{20}$ by recording method used to generate the randomisation schedule and conceal allocation, whether blinding was implemented, what proportion of patients completed follow-up, whether an intention-to-treat analysis was extractable, and whether there was evidence of selective reporting of outcomes.

\section{Data synthesis and statistical analysis}

Data were pooled using a random effects model, to give a more conservative estimate of the effect of laxatives and pharmacological therapies in CIC, allowing for any heterogeneity between studies. ${ }^{21}$ Impact on overall response to therapy in CIC was expressed as a RR of failure to respond to therapy compared 
with placebo at last time point of assessment in the trial, or a weighted mean difference (WMD) in mean number of stools per week during therapy, with 95\% CIs. Individual CIC symptom data and adverse events data were also summarised with relative risks. The number needed to treat (NNT) and the number needed to harm (NNH) with $95 \%$ CIs were calculated from the reciprocal of the risk difference of the meta-analysis.

Heterogeneity between studies was assessed using both the $\mathrm{I}^{2}$ statistic with a cut-off of $\geq 50 \%,{ }^{22}$ and the $\chi^{2}$ test with a $p$ value $<0.10$, used to define a significant degree of heterogeneity. We conducted a priori sensitivity analyses according to type of laxative used, dose of pharmacological therapy, risk of bias of identified trials, criteria used to define CIC, duration of therapy, and criteria used to define response to therapy. These were exploratory analyses only, and may explain some of the observed variability, but the results should be interpreted with caution.

Review Manager version 5.0.23 (RevMan for Windows 2008; the Nordic Cochrane Center, Copenhagen, Denmark) and StatsDirect version 2.7.7 (StatsDirect Ltd, Sale, Cheshire, UK) were used to generate Forest plots for primary and secondary outcomes with $95 \%$ CIs, as well as funnel plots. The latter were assessed for evidence of asymmetry, and therefore possible publication bias or other small study effects, using the Egger and Begg tests. ${ }^{23}$

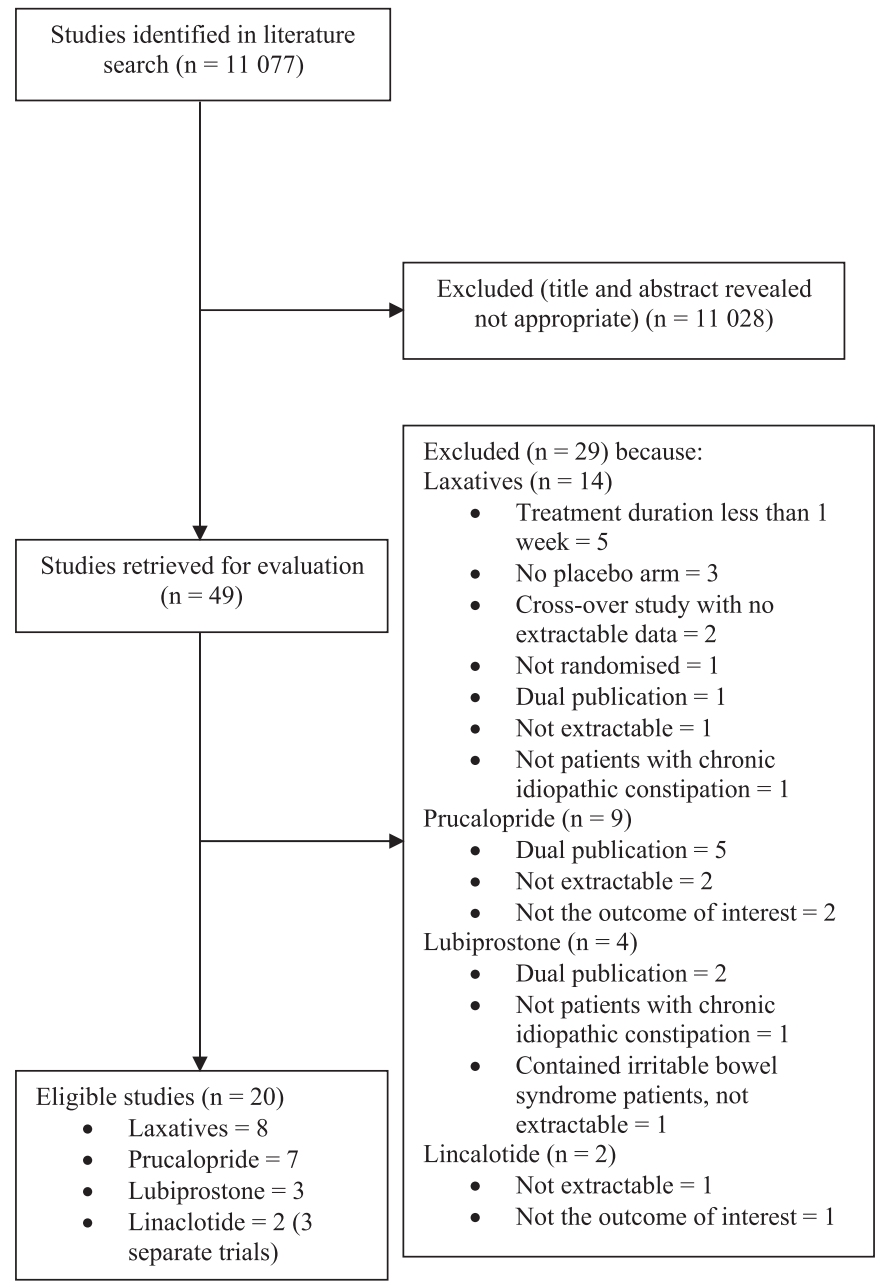

Figure 1 Flow diagram of assessment of studies identified in the systematic review.

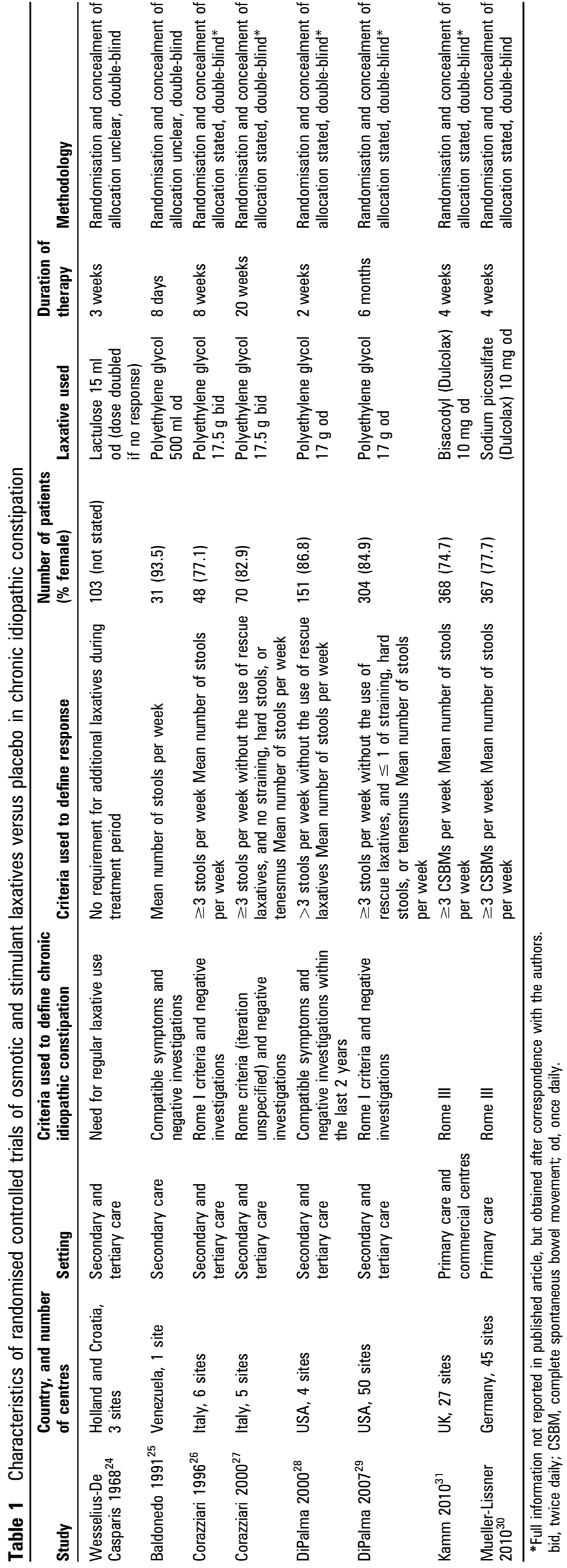


Figure 2 Forest plot of randomised controlled trials of laxatives versus placebo in chronic idiopathic constipation.

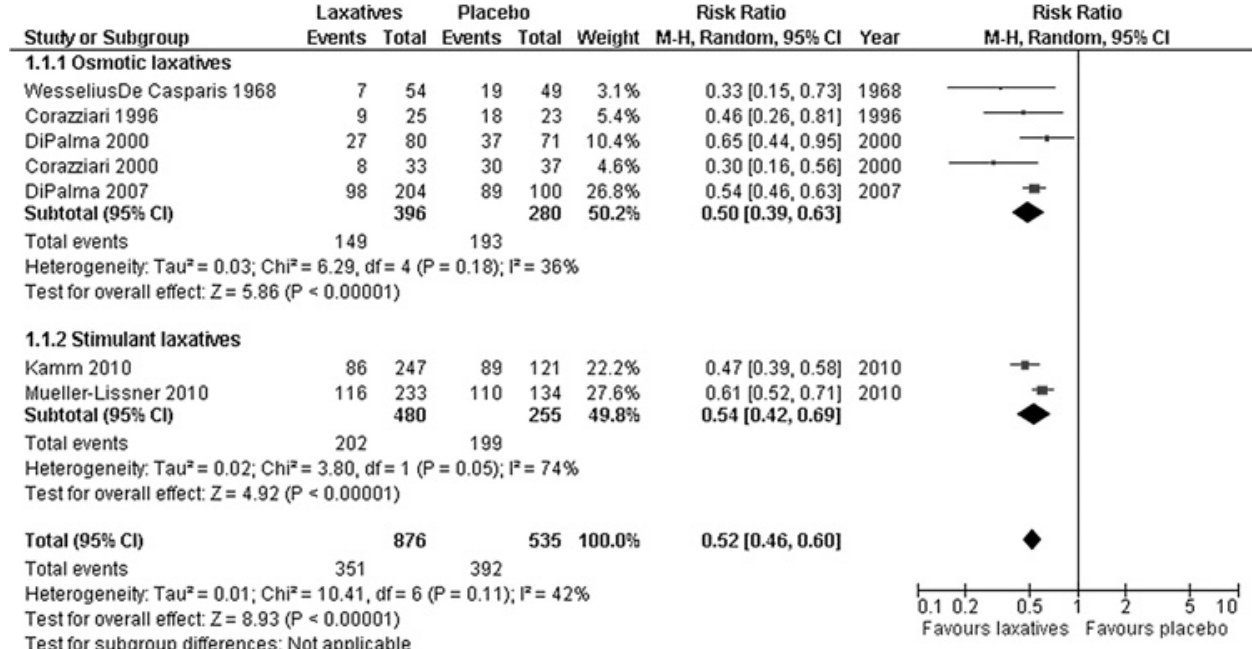

\section{RESULTS}

The search strategy generated 11077 citations, 49 of which appeared to be relevant to the systematic review and were retrieved for further assessment (figure 1). Of these, 29 were excluded for various reasons, leaving a total of 20 eligible articles reporting 21 separate trials. Eight RCTs studied the effect of laxatives, ${ }^{24-31}$ seven prucalopride, ${ }^{32-38}$ three lubiprostone, ${ }^{39-41}$ and three linaclotide. ${ }^{42}$ We contacted authors of seven of the trials successfully to obtain supplementary information about the methodology used. ${ }^{26-31} 43$ Agreement between investigators for trial eligibility was substantial ( $\kappa$ statistic $=0.83$ ).

\section{Efficacy and safety of laxatives in CIC}

The eight RCTs comparing laxatives with placebo, involved a total of 1442 CIC patients (table 1 ). ${ }^{24-31}$ Five trials were at low risk of bias. ${ }^{27-31}$ Rescue laxatives were allowed if there was no bowel movement for 3 days in one trial, ${ }^{24} 4$ days in three trials, ${ }^{29-31}$ and 5 days in two trials, ${ }^{2627}$ and in the remaining two trials this issue was unclear. ${ }^{25} 28$

\section{Response to therapy with laxatives}

Dichotomous data were reported by seven RCTs, ${ }^{24}$ 26-31 containing 1411 patients. There were 351 (40.1\%) of 876 patients assigned to laxatives who failed to respond to therapy, compared with $392(73.3 \%)$ of 535 allocated to placebo (RR of failure to respond $=0.52 ; 95 \%$ CI 0.46 to 0.60 ), with borderline heterogeneity between studies $\left(\mathrm{I}^{2}=42 \%, \mathrm{p}=0.11\right)$ (figure 2$)$. The NNTwith laxatives to prevent failure of response in one CIC patient was 3 (95\% CI 2 to 4). There was no statistically significant funnel plot asymmetry (Egger test, $p=0.15$ and Begg test, $p=0.08$ ) suggesting no evidence of publication bias or other small study effects.

Of the six studies comparing osmotic laxatives with placebo, ${ }^{24-29}$ five reported dichotomous data in 676 patients. $^{24}{ }^{26-29}$ Overall, 149 (37.6\%) of 396 patients assigned to osmotic laxatives failed to respond to therapy compared with $193(68.9 \%)$ of 280 patients allocated to placebo ( $R R=0.50$; $95 \%$ CI 0.39 to 0.63 ) (figure 2), with no significant heterogeneity between studies $\left(\mathrm{I}^{2}=36 \%, \mathrm{p}=0.18\right)$. The NNT with osmotic laxatives was 3 (95\% CI 2 to 4). There was no evidence of funnel plot asymmetry (Egger test, $\mathrm{p}=0.26$ and Begg test, $\mathrm{p}=0.08$ ).

Both trials of stimulant laxatives, containing 735 patients, reported dichotomous data. ${ }^{30}{ }^{31}$ In total, 202 (42.1\%) of 480 patients randomised to stimulant laxatives failed to respond to therapy, compared with 199 (78.0\%) of 255 patients receiving placebo ( $\mathrm{RR}=0.54 ; 95 \% \mathrm{CI} 0.42$ to 0.69 ) (figure 2$)$. The NNT with stimulant laxatives was 3 (95\% CI 2 to 3.5).

Given the borderline heterogeneity observed when results of individual RCTs were combined, we conducted pre-specified

Table 2 Sensitivity analyses of efficacy of osmotic and stimulant laxatives in chronic idiopathic constipation

\begin{tabular}{|c|c|c|c|c|c|c|c|}
\hline & $\begin{array}{l}\text { Number of } \\
\text { studies }\end{array}$ & $\begin{array}{l}\text { Number of } \\
\text { subjects }\end{array}$ & $\begin{array}{l}\text { RR of failure } \\
\text { to respond } \\
\text { to therapy }\end{array}$ & $95 \% \mathrm{CI}$ & $I^{2}$ value & $\begin{array}{l}\text { Number } \\
\text { needed } \\
\text { to treat }\end{array}$ & $95 \% \mathrm{CI}$ \\
\hline All studies & 7 & 1411 & 0.52 & 0.46 to 0.60 & $42 \%$ & 3 & 2 to 4 \\
\hline \multicolumn{8}{|l|}{ Risk of bias of trials } \\
\hline Low & 5 & 1260 & 0.54 & 0.46 to 0.62 & $52 \%$ & 3 & 2 to 4 \\
\hline High & 2 & 151 & 0.41 & 0.26 to 0.65 & $\mathrm{~N} / \mathrm{A}$ & 3 & 2 to 6 \\
\hline \multicolumn{8}{|l|}{ Definition of CIC } \\
\hline Rome criteria-defined & 5 & 1157 & 0.52 & 0.45 to 0.61 & $50 \%$ & 2.5 & 2 to 3 \\
\hline Other definition & 2 & 254 & 0.51 & 0.27 to 0.96 & $\mathrm{~N} / \mathrm{A}$ & 4.5 & 3 to 9 \\
\hline \multicolumn{8}{|l|}{ Duration of therapy } \\
\hline$\leq 4$ weeks & 4 & 989 & 0.54 & 0.45 to 0.66 & $51 \%$ & 3 & 2.5 to 4 \\
\hline$>4$ weeks & 3 & 422 & 0.46 & 0.33 to 0.65 & $49 \%$ & 2.5 & 2 to 3 \\
\hline \multicolumn{8}{|c|}{ Definition of response to therapy } \\
\hline$\geq 3$ stools per week & 4 & 573 & 0.52 & 0.41 to 0.65 & $36 \%$ & 3 & 2 to 4 \\
\hline$\geq 3$ CSBMs per week & 2 & 735 & 0.54 & 0.42 to 0.69 & NA & 3 & 2 to 3.5 \\
\hline
\end{tabular}

N/A, not applicable (too few studies to assess heterogeneity); CIC, chronic idiopathic constipation; CSBM, complete spontaneous bowel movement. 
sensitivity analyses (table 2). Both the RR of failure to respond and the NNT were relatively stable in all these analyses, although heterogeneity between trials was lower when only the four studies that used three or more stools per week to define response to therapy were included in the analysis. ${ }^{26-29}$ Treatment effect remained similar when only the five trials at low risk of bias were considered. ${ }^{27-31}$

Only three RCTs reported data concerning individual CIC symptoms. ${ }^{26-28}$ Two studies, containing 118 patients, provided data on straining at stool, ${ }^{26} 27$ and data concerning hardness of stools during therapy were provided by all three trials, containing 269 patients. ${ }^{26-28}$ The RR of both were significantly reduced with laxatives $(0.37 ; 95 \%$ CI 0.19 to 0.71 and $0.26 ; 95 \%$ CI 0.16 to 0.44 respectively).

Mean number of stools per week with laxatives

Continuous data were reported by six studies containing 1269 patients. $^{25} 2628-31$ Mean number of stools per week was significantly higher with laxatives compared with placebo (WMD in number of stools per week $=2.55 ; 95 \%$ CI 1.53 to 3.57 ) (figure 3), with statistically significant heterogeneity between studies $\left(\mathrm{I}^{2}=100 \%, \mathrm{p}<0.001\right)$, but no evidence of funnel plot asymmetry (Egger test, $p=0.70$ and Begg test, $p=0.27$ ). This beneficial effect appeared to exist for both osmotic $(\mathrm{WMD}=2.51$; $95 \%$ CI 1.30 to 3.71$),{ }^{25} 262829$ and stimulant laxatives $(\mathrm{WMD}=2.50 ; 95 \% \mathrm{CI} 0.93$ to 4.07$) .{ }^{30} 31$

\section{Adverse events with laxatives}

Only one RCT reported total numbers of adverse events, in 368 patients. $^{31}$ The RR of experiencing any adverse event with laxatives was 1.94 (95\% CI 1.52 to 2.47 , NNH=3; 95\% CI 2 to 4$)$. In terms of individual adverse events, four trials reported these data. ${ }^{26273031}$ No significant differences were detected in rates of abdominal pain, reported in all four trials containing 853 patients, or headache, reported in three RCTs containing 486 patients. ${ }^{262731}$ Diarrhoea occurred significantly more frequently in two trials containing 735 patients $(R R=13.75$; $95 \%$ CI 2.82 to 67.14, $\mathrm{NNH}=3$; 95\% CI 2 to 6). ${ }^{30} 31$

\section{Efficacy and safety of prucalopride in CIC}

The seven RCTs comparing prucalopride with placebo involved 2639 CIC patients (table 3). ${ }^{32-38}$ Three trials were at low risk of bias. $^{353638}$ Rescue laxatives were allowed if there was no bowel movement for 3 or more consecutive days in six of the trials, ${ }^{33-38}$ and in the remaining trial this issue was unclear. $^{32}$ Two trials recruited patients either resistant to, or dissatisfied with, laxatives, ${ }^{34} 37$ and one trial only recruited patients aged over 65 years. $^{38}$ Only one trial reported extractable data concerning mean number of stools per week, ${ }^{33}$ so no data were pooled. Effect on individual CIC symptom data was not reported in any RCT.

\section{Response to therapy with prucalopride}

There were 1288 (71.7\%) of 1796 patients receiving prucalopride who failed to respond to therapy, compared with $731(86.7 \%)$ of 843 allocated to placebo (RR of failure to respond to therapy $=0.82 ; 95 \%$ CI 0.76 to 0.88$)$, with significant heterogeneity between studies $\left(\mathrm{I}^{2}=60 \%, \mathrm{p}=0.02\right)$ (figure 4), and an NNT of 6 (95\% CI 5 to 9$)$. There was borderline statistically significant funnel plot asymmetry (Egger test, $p=0.04$ and Begg test, $p=0.07$ ) suggesting publication bias or other small study effects, though this was driven by one small study, ${ }^{33}$ and disappeared with its exclusion from the analysis.

Given the significant heterogeneity observed when results of individual RCTs were combined, we conducted pre-specified sensitivity analyses (table 4). Heterogeneity was no longer significant when trials that used three or more CSBMs per week to define response to therapy were considered in the analysis, ${ }^{32}{ }^{35-38}$ when only the three trials at low risk of bias were included, ${ }^{35} 3638$ and when the six trials that used the modified Rome II criteria were pooled. ${ }^{32} 34-38$ The NNT fell when only high risk of bias trials were included, ${ }^{32-34} 37$ and when trials using more than 4 weeks of therapy were excluded. $^{35-37}$ Analyses according to dose of prucalopride used demonstrated similar efficacy for $2 \mathrm{mg}$ and $4 \mathrm{mg}$ once daily.

\section{Adverse events with prucalopride}

Six trials reported total numbers of adverse events, ${ }^{33-38}$ which were more common with prucalopride than with placebo $(\mathrm{RR}=1.14 ; 95 \% \mathrm{CI} 1.05$ to $1.24, \mathrm{NNH}=10 ; 95 \% \mathrm{CI} 6$ to 29$)$. Individual adverse events including headache (RR $1.70 ; 95 \% \mathrm{CI}$ 1.25 to 2.31 ), nausea ( $R R=1.98 ; 95 \%$ CI 1.39 to 2.82$)$, and diarrhoea ( $R R=2.72$; 95\% CI 1.80 to 4.13 ) were all more common with prucalopride. There was no significant increase in serious adverse event rates detected with prucalopride $(\mathrm{RR}=0.88 ; 95 \%$ CI 0.58 to 1.34 ), and there was only one cardiovascular event reported with the drug, ${ }^{35}$ an episode of supraventricular tachycardia. There were no significant differences detected in any adverse events rates between $2 \mathrm{mg}$ and $4 \mathrm{mg}$ doses of prucalopride (data not shown).

\section{Efficacy and safety of lubiprostone in CIC}

The three RCTs comparing lubiprostone with placebo contained 610 patients with CIC (table 3). ${ }^{39-41}$ One trial was at low risk of bias. ${ }^{41}$ Rescue laxatives were allowed if there was no bowel movement for 3 or more consecutive days in all RCTs. No trials
Figure 3 Weighted mean difference in number of stools per week during therapy with laxatives versus placebo in chronic idiopathic constipation.

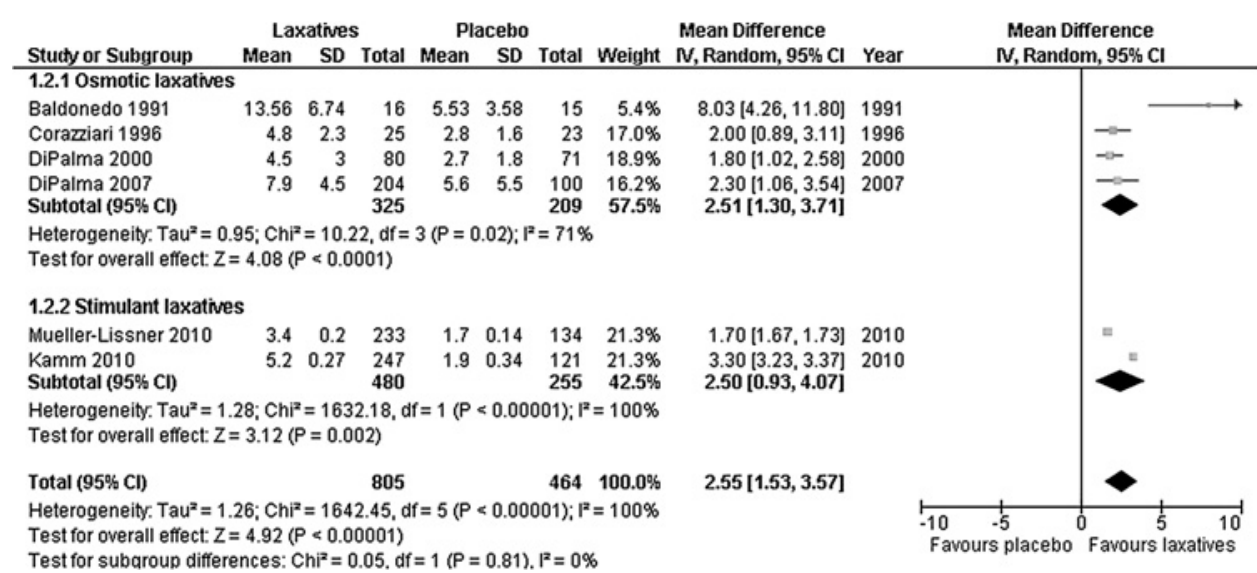




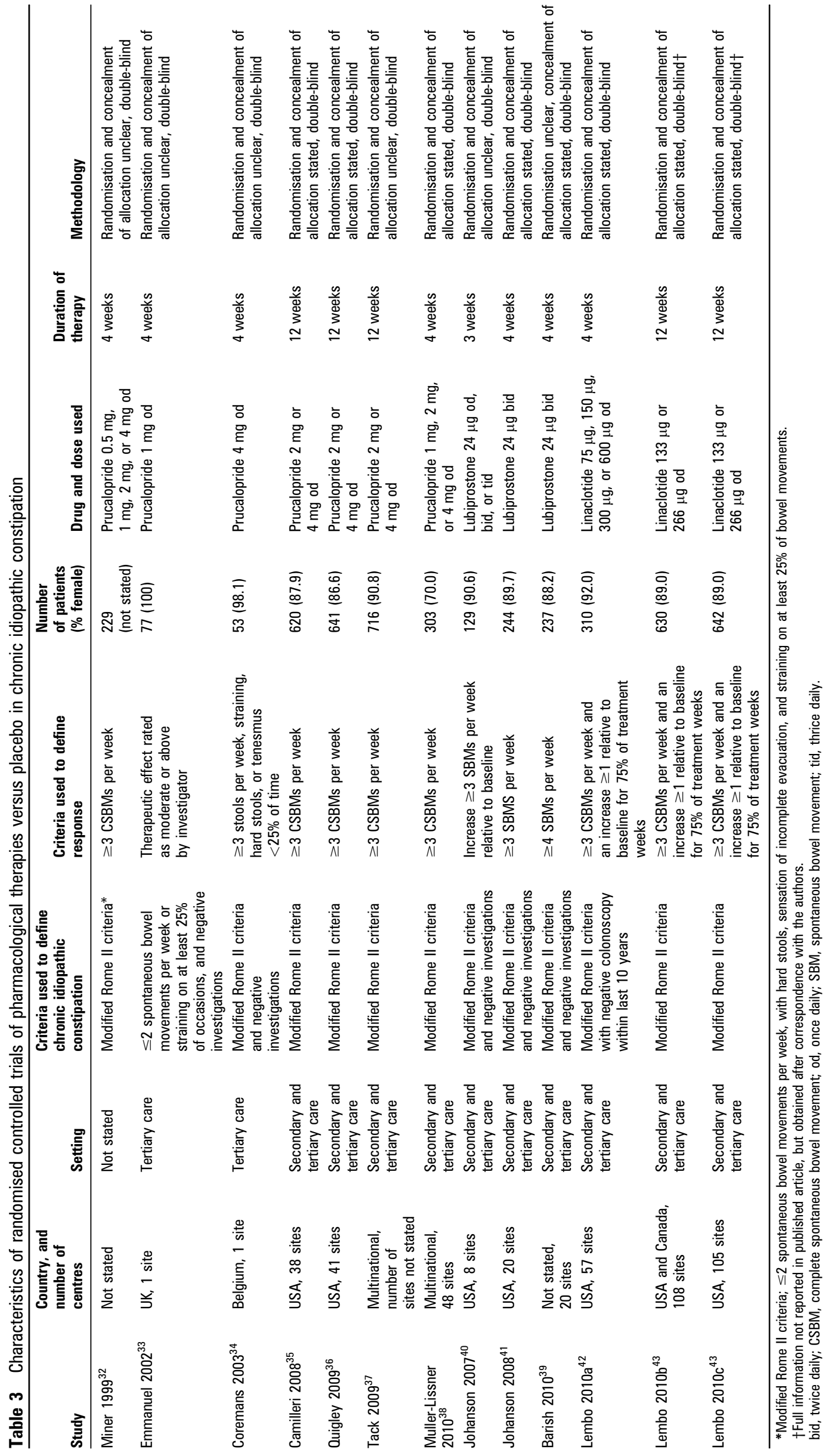


Figure 4 Forest plot of randomised controlled trials of prucalopride versus placebo in chronic idiopathic constipation.

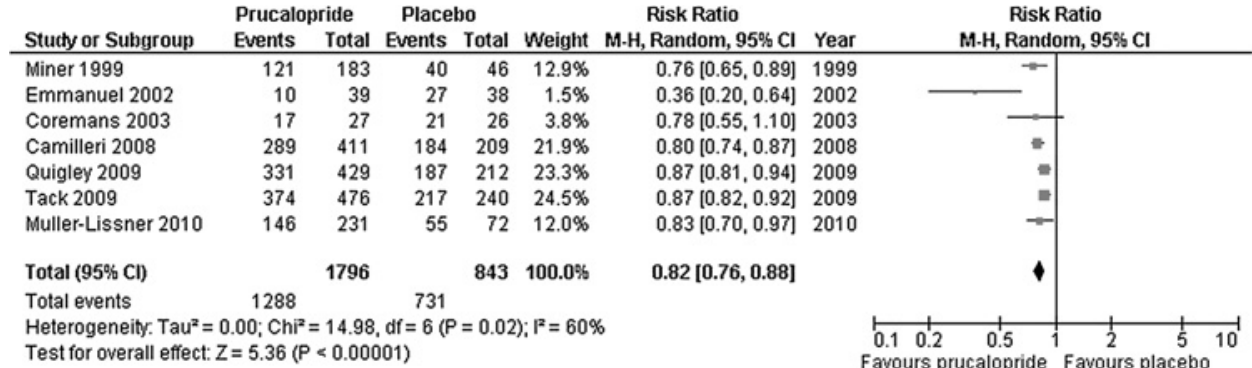

Favours prucalopride Favours placebo reported extractable data concerning mean number of stools per week, or effect on individual CIC symptoms.

\section{Response to therapy with lubiprostone}

There were 151 (45.1\%) of 335 patients receiving lubiprostone who failed to respond to therapy, compared with 184 (66.9\%) of 275 placebo patients ( $R R$ of failure to respond to therapy $=0.67$; $95 \%$ CI 0.56 to 0.80 ), with no significant heterogeneity between studies $\left(\mathrm{I}^{2}=30 \%, \mathrm{p}=0.24\right)$ (figure 5$)$. The NNT was 4 (95\% CI 3 to 7). There were too few studies to assess for funnel plot asymmetry, or perform pre-specified sensitivity analyses. One trial was a dose-ranging study, ${ }^{40}$ but all three RCTs used a dose of $24 \mu \mathrm{g}$ twice daily. When only this dose was considered in the analysis treatment effect remained very similar $(R R=0.64 ; 95 \%$ CI 0.55 to 0.76 ).

\section{Adverse events with lubiprostone}

All trials reported adverse events data. Total numbers of adverse events were significantly higher with lubiprostone $(R R=1.79$; $95 \%$ CI 1.21 to $2.65, \mathrm{NNH}=4 ; 95 \%$ CI 3 to 6). Diarrhoea $(\mathrm{RR}=4.46 ; 95 \%$ CI 1.28 to 15.48$)$ and nausea ( $R R=7.27 ; 95 \% \mathrm{CI}$ 3.76 to 14.06 ) both occurred significantly more frequently with lubiprostone, but no significant difference in rates of abdominal pain or headache were detected.

\section{Efficacy and safety of linaclotide in CIC}

The three RCTs comparing linaclotide with placebo contained 1582 CIC patients (table 3). ${ }^{42}$ All three were at low risk of bias. Rescue laxatives were allowed if there was no bowel movement for 3 or more consecutive days in all RCTs. No trial reported extractable data concerning mean number of stools per week Individual CIC symptom data were reported in one RCT. ${ }^{42}$

\section{Response to therapy with linaclotide}

Overall, 860 (79.0\%) of 1089 patients receiving linaclotide failed to respond to therapy, compared with 468 (94.9\%) of 493 placebo patients ( $R R$ of failure to respond to therapy $=0.84$; $95 \%$ CI 0.80 to 0.87 ), with no significant heterogeneity between studies $\left(\mathrm{I}^{2}=32 \%, \mathrm{p}=0.23\right.$ ) (figure 6 ), and an NNT of 6 ( $95 \%$ CI 5 to 8). Again there were insufficient studies to assess for funnel plot asymmetry, or perform sensitivity analyses. Analyses according to dose of linaclotide used demonstrated similar efficacy for $133 \mu \mathrm{g}$ and $266 \mu \mathrm{g}$ once daily ( $\mathrm{RR}=0.85$; $95 \% \mathrm{CI} 0.78$ to 0.94 and $0.84 ; 95 \%$ CI 0.79 to 0.88 respectively). Linaclotide also led to a significantly higher proportion of patients reporting a decrease in severity of abdominal discomfort and bloating. ${ }^{42}$

\section{Adverse events with linaclotide}

Only one trial reported total adverse event rates, ${ }^{42}$ which were very similar in number in both treatment arms (33.6\% linaclotide vs $31.9 \%$ placebo). Serious adverse events occurred in two placebo patients. All three trials reported occurrence of diarrhoea, ${ }^{42}{ }^{43}$ which was commoner with linaclotide $(R R=3.08$; $95 \%$ CI 1.27 to 7.48$)$.

\section{DISCUSSION}

This systematic review and meta-analysis has demonstrated that both laxatives and pharmacological therapies are more

Table 4 Sensitivity analyses of efficacy of prucalopride in chronic idiopathic constipation.

\begin{tabular}{|c|c|c|c|c|c|c|c|}
\hline & $\begin{array}{l}\text { Number of } \\
\text { studies }\end{array}$ & $\begin{array}{l}\text { Number of } \\
\text { subjects }\end{array}$ & $\begin{array}{l}\text { RR of failure } \\
\text { to respond } \\
\text { to therapy }\end{array}$ & $95 \% \mathrm{Cl}$ & $I^{2}$ value & $\begin{array}{l}\text { Number } \\
\text { needed } \\
\text { to treat }\end{array}$ & $95 \% \mathrm{Cl}$ \\
\hline All studies & 7 & 2639 & 0.82 & 0.76 to 0.88 & $60 \%$ & 6 & 5 to 9 \\
\hline \multicolumn{8}{|l|}{ Risk of bias of trials } \\
\hline Low & 3 & 1564 & 0.84 & 0.79 to 0.89 & $29 \%$ & 7 & 5 to 10 \\
\hline High & 4 & 1075 & 0.75 & 0.61 to 0.92 & $77 \%$ & 5 & 3 to 11 \\
\hline \multicolumn{8}{|l|}{ Definition of CIC } \\
\hline Rome II criteria & 6 & 2562 & 0.84 & 0.81 to 0.88 & $13 \%$ & 7 & 6 to 9 \\
\hline Other criteria & 1 & 77 & 0.36 & 0.20 to 0.64 & $\mathrm{~N} / \mathrm{A}$ & 2 & 1.5 to 4 \\
\hline \multicolumn{8}{|l|}{ Duration of therapy } \\
\hline$\leq 4$ weeks & 4 & 662 & 0.73 & 0.60 to 0.90 & $64 \%$ & 4 & 3 to 10 \\
\hline$>4$ weeks & 3 & 1977 & 0.85 & 0.81 to 0.90 & $42 \%$ & 8 & 6 to 11 \\
\hline \multicolumn{8}{|c|}{ Definition of response to therapy } \\
\hline$\geq 3$ CSBMs per week & 5 & 2509 & 0.84 & 0.80 to 0.88 & $28 \%$ & 7 & 6 to 9 \\
\hline Other definition & 2 & 130 & 0.55 & 0.24 to 1.25 & $84 \%$ & $\mathrm{~N} / \mathrm{A}$ & $\mathrm{N} / \mathrm{A}$ \\
\hline \multicolumn{8}{|c|}{ Dose of prucalopride used } \\
\hline $1 \mathrm{mg} \mathrm{od}$ & 3 & 319 & 0.68 & 0.46 to 1.00 & $82 \%$ & $\mathrm{~N} / \mathrm{A}$ & $\mathrm{N} / \mathrm{A}$ \\
\hline $2 \mathrm{mg} \mathrm{od}$ & 5 & 1560 & 0.85 & 0.80 to 0.90 & $18 \%$ & 8 & 6 to 11 \\
\hline $4 \mathrm{mg} \mathrm{od}$ & 6 & 1615 & 0.83 & 0.77 to 0.90 & $52 \%$ & 6 & 5 to 11 \\
\hline
\end{tabular}

N/A, not applicable; CIC, chronic idiopathic constipation; CSBM, complete spontaneous bowel movement; od, once daily. 
Figure 5 Forest plot of randomised controlled trials of lubiprostone versus placebo in chronic idiopathic constipation.

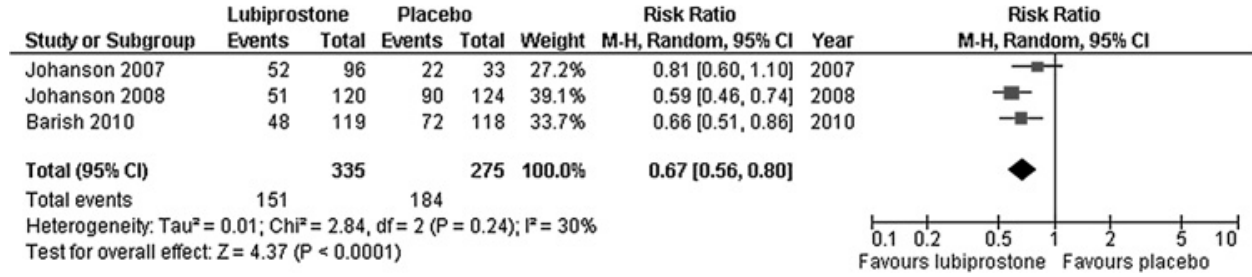

primary care, ${ }^{30}{ }^{31}$ meaning that individuals involved in the meta-analysis may not be truly generalisable to patients consulting their general practitioner with CIC, and most trials recruited predominantly female patients. There were fewer trials reporting efficacy of the stimulant laxatives sodium picosulfate and bisacodyl (which are converted to the same active metabolite), ${ }^{30}{ }^{31}$ lubiprostone and linaclotide, but all contained large numbers of individuals with CIC and were rigorously designed. There was borderline heterogeneity when data from laxative studies were pooled, and definite heterogeneity between prucalopride trials, but our sensitivity analyses revealed plausible explanations for this. In addition, trials reporting effect of therapy on individual symptoms of CIC, such as straining and passage of hard stools, were scarce. Finally, total and individual adverse events data were reported in few laxative or linaclotide studies, though as two of the latter three RCTs were published in abstract form only this is unavoidable.

There have been four previous systematic reviews examining efficacy of laxatives in CIC. ${ }^{16}{ }^{44-46}$ One of these was descriptive and did not perform a formal meta-analysis. ${ }^{16}$ Two were conflicting, ${ }^{44}{ }^{45}$ with one reporting a significant effect of laxatives, ${ }^{45}$ and the other failing to demonstrate any distinguishable effect from placebo. ${ }^{44}$ This led the authors of the latter study to conclude that better evidence was required to justify the continued expenditure by both CIC patients and formularies on laxatives. There have been considerable data published in the years since both these studies were conducted. The fourth study, a recent meta-analysis of 10 placebo-controlled trials of PEG in non-organic constipation, reported a beneficial effect. ${ }^{46}$ However, the authors included RCTs of PEG conducted in opiate-induced constipation, ${ }^{47}$ patients with constipation induced by other drugs, ${ }^{48}$ and institutionalised patients, ${ }^{49}$ rather than trials conducted only in patients with CIC. In addition, there was no minimum duration of therapy, with included studies using only 4 or 5 days of therapy. ${ }^{50} 51$ All these trials were identified by our search strategy and excluded during eligibility assessment. There has been no meta-analysis of newer pharmacological therapies performed, to our knowledge, to date. These limitations of previous systematic reviews and metaanalyses of laxatives, together with the lack of a previous quantitative analysis of the efficacy of newer pharmacological therapies, emphasise the need for a definitive study, such as ours, in this area.

Current guidelines for the management of CIC from national and international gastroenterological associations do not make strong recommendations for the use of either laxatives or pharmacological therapies. ${ }^{15-17}$ Evidence from this systematic
Figure 6 Forest plot of randomised controlled trials of linaclotide versus placebo in chronic idiopathic constipation.

\begin{tabular}{|c|c|c|c|c|c|c|c|c|c|}
\hline Stucty or Subgroup & \multicolumn{2}{|c|}{ Linaclotide } & \multicolumn{2}{|c|}{ Placebo } & Weight & $\begin{array}{c}\text { Risk Ratio } \\
\text { M.H, Random, } 95 \% \mathrm{Cl}\end{array}$ & \multicolumn{3}{|c|}{$\begin{array}{c}\text { Risk Ratio } \\
\text { M.H, Random, } 95 \% \mathrm{Cl}\end{array}$} \\
\hline Lembo 2010a & 177 & 241 & 64 & 69 & $17.4 \%$ & $0.79[0.72,0.88]$ & - & & \\
\hline Lembo $2010 \mathrm{~b}$ & 338 & 415 & 202 & 215 & $39.9 \%$ & $0.87[0.82,0.92]$ & ㅁ & & \\
\hline Lembo $2010 c$ & 345 & 433 & 202 & 209 & $42.8 \%$ & $0.82[0.78,0.87]$ & $\mathbf{\square}$ & & \\
\hline Total $(95 \% \mathrm{Cl})$ & & 1089 & & 493 & $100.0 \%$ & $0.84[0.80,0.87]$ & 1 & & \\
\hline Total events & 860 & & 468 & & & & & & \\
\hline $\begin{array}{l}\text { Heterogeneity: Tauz } \\
\text { Test for overall effect }\end{array}$ & $\begin{array}{l}0.00 ; \mathrm{Chi} \\
\mathrm{z}=7.68\end{array}$ & $\begin{array}{l}=2.93 \\
P<0.0\end{array}$ & $\begin{array}{l}\text { df }=2(P \\
0001)\end{array}$ & $=0.23$ & 3); $1^{2}=329$ & & \begin{tabular}{|ccc} 
& 1 & 1 \\
0.1 & 0.2 & 0.5 \\
Favours linaclotide
\end{tabular} & $1 \frac{2}{2}$ & $\underset{5}{510}$ \\
\hline
\end{tabular}


review and meta-analysis supports the use of old-fashioned, and perhaps neglected, therapies such as PEG, sodium picosulfate and bisacodyl for the treatment of CIC, but also the newer pharmacological agents. While NNTs were generally lower for laxatives, this probably reflects a combination of more stringent endpoints in trials of pharmacological therapies, and the fact that the latter trials are likely to have recruited a more recalcitrant patient population, who had already failed or were dissatisfied with laxative therapy.

Total numbers of adverse events were significantly more common with laxatives than with placebo in one trial, and with both prucalopride and lubiprostone. In addition, diarrhoea occurred significantly more frequently in individuals receiving all the therapies studied, and nausea was reported by significantly more patients receiving prucalopride and lubiprostone. Serious adverse events were no more frequent with active therapy. It should be stressed that, while these treatments appear safe in the short term, their longer-term safety profile remains relatively unknown. Long-term safety data are now emerging for prucalopride and, after almost 3 years of open-label therapy, less than $10 \%$ of individuals discontinued the drug due to adverse events. ${ }^{52}$ More RCTs of all these pharmacological agents are in progress, and the results are awaited with interest. This, together with the fact that newer agents for the treatment of CIC, which also appear to be effective, ${ }^{53}$ are in development should provide both patients with CIC and physicians with reasons for cautious optimism.

In summary, this systematic review and meta-analysis has demonstrated that laxatives, prucalopride, lubiprostone and linaclotide are all superior to placebo for the treatment of CIC. It should, however, be noted that between $50 \%$ and $85 \%$ of patients did not fulfil criteria for response to therapy when data from studies were pooled. Further large studies of these agents in primary care are required, ideally with head-to-head comparison of their efficacy.

Acknowledgements We are grateful to Drs Enrico Corazziari, Jack A DiPalma, Ulrika Hinkel and Anthony $J$ Lembo for responding to our queries regarding their studies.

\section{Competing interests None.}

Contributors Alexander $C$ Ford acts as guarantor for the validity of the study report. Study concept and design: ACF, NCS. Acquisition of data: ACF, NCS. Analysis and interpretation of data: ACF, NCS. Drafting of the manuscript: ACF. Critical revision of the manuscript for important intellectual content: ACF, NCS. Statistical analysis: ACF, NCS.

Provenance and peer review Not commissioned; externally peer reviewed.

\section{REFERENCES}

1. Longstreth GF, Thompson WG, Chey WD, et al. Functional bowel disorders. Gastroenterology 2006;130:1480-91

2. Drossman DA, Li Z, Andruzzi E, et al. U.S. householder survey of functional gastrointestinal disorders. Prevalence, sociodemography, and health impact. Dig Dis Sci 1993;38:1569-80.

3. Walter S, Hallbook 0, Gotthard R, et al. A population-based study on bowel habits in a Swedish community: prevalence of faecal incontinence and constipation. Scand J Gastroenterol 2002;37:911-16.

4. Stewart WF, Liberman JN, Sandler RS, et al. Epidemiology of constipation (EPOC) study in the United States: relation of clinical subtypes to sociodemographic features. Am J Gastroenterol 1999;94:3530-40.

5. Talley NJ, Weaver AL, Zinsmeister AR, et al. Functional constipation and outlet delay: a population-based study. Gastroenterology 1993;105:781-90.

6. Wald A, Scarpignato C, Mueller-Lissner S, et al. A multinational survey of prevalence and patterns of laxative use among adults with self-defined constipation. Aliment Pharmacol Ther 2008;28:917-30.

7. Everhart JE, Go VL, Johannes RS, et al. A longitudinal survey of self-reported bowel habits in the United States. Dig Dis Sci 1989;34:1153-62.

8. Wald A, Scarpignato C, Kamm MA, et al. The burden of chronic constipation on quality of life: results of a multinational survey. Aliment Pharmacol Ther 2007:26:227-36.
9. Badiali D, Corazziari E, Habib Fl, et al. Effect of wheat bran in treatment of chronic non-organic constipation. A double-blind controlled trial. Dig Dis Sci 1995; 40:349-56.

10. Ashraf W, Park F, Lof J, et al. Effects of psyllium therapy on stool characteristics, colon transit and anorectal function in chronic idiopathic constipation. Aliment Pharmacol Ther 1995; 9:639-47.

11. Johanson JF, Kralstein J. Chronic constipation: a survey of the patient perspective Aliment Pharmacol Ther 2007;25:599-608.

12. Bouras EP, Camilleri M, Burton DP, et al. Prucalopride accelerates gastrointestina and colonic transit in patients with constipation without a rectal evacuation disorder Gastroenterology 2001;120:354-60.

13. Camilleri M, Barucha AE, Ueno R, et al. Effect of a selective chloride channel activator, lubiprostone, on gastrointestinal transit, gastric sensory, and motor functions in healthy volunteers. Am J Physiol Gastrointest Liver Physiol 2006;290:942-7.

14. Bryant AP, Busby RW, Bartolini WP, et al. Linaclotide is a potent and selective guanylate cyclase $C$ agonist that elicits pharmacological effects locally in the gastrointestinal tract. Life Sci 2010:86:760-5.

15. Locke GR, Pemberton JH, Phillips SF. AGA technical review on constipation. Gastroenterology 2000;119:1766-78

16. Ramkumar D, Rao SSC. Efficacy and safety of traditional medical therapies for chronic constipation: systematic review. Am J Gastroenterol 2005;100:936-71.

17. World Gastroenterology Organisation practice guidelines: Constipation. http://www. worldgastroenterology.org/assets/downloads/en/pdf/guidelines/05 constipation.pdf.

18. Thompson WG, Longstreth GF, Drossman DA, et al. Functional bowel disorders and functional abdominal pain. Gut 1999;45 (Suppl II):I143-7.

19. Whitehead WE, Chaussade S, Corazziari E, et al. Report of an international workshop on management of constipation. Gastroenterol Int 1991;4:99-113.

20. Higgins JPT, Green S. Cochrane handbook for systematic reviews of interventions: version 5.0.2. http://www.cochrane-handbook.org (accessed 2010).

21. DerSimonian R, Laird N. Meta-analysis in clinical trials. Control Clin Trials 1986; 7:177-88.

22. Higgins JP, Thompson SG. Quantifying heterogeneity in a meta-analysis. Stat Med 2002; 21:1539-58.

23. Egger M, Davey-Smith G, Schneider M, et al. Bias in meta-analysis detected by a simple, graphical test. Br Med J 1997;315:629-34.

24. Wesselius-De Casparis A, Braadbaart S, Bergh-Bohlken GE, et al. Treatment of chronic constipation with lactulose syrup: results of a double-blind study. Gut 1968:9:84-6.

25. Baldonedo YC, Lugo E, Uzcategui AA, et al. [Evaluation and use of polyethylene glycol in constipated patients]. G EN 1991;45:294-7.

26. Corazziari $\mathbf{E}$, Badiali D, Habib Fl, et al. Small volume isosmotic polyethylene glyco electrolyte balanced solution (PMF-100) in treatment of chronic nonorganic constipation. Dig Dis Sci 1996;41:1636-42.

27. Corazziari E, Badiali D, Bazzocchi G, et al. Long term efficacy, safety, and tolerability of low daily doses of isosmotic polyethylene glycol electrolyte balanced solution (PMF-100) in the treatment of functional chronic constipation. Gut 2000;46:522-6.

28. DiPalma JA, DeRidder PH, Orlando RC, et al. A randomized, placebo-controlled, multicenter study of the safety and efficacy of a new polyethylene glycol laxative. Am J Gastroenterol 2000;95:446-50.

29. DiPalma JA, Cleveland MV, McGowan J, et al. A randomized, multicenter, placebo-controlled trial of polyethylene glycol laxative for chronic treatment of chronic constipation. Am J Gastroenterol 2007;102:1436-41.

30. Mueller-Lissner S, Kamm MA, Wald A, et al. Multicenter, 4-week, double-blind, randomized, placebo-controlled trial of sodium picosulfate in patients with chronic constipation. Am J Gastroenterol 2010:105:897-903.

31. Kamm MA, Mueller-Lissner S, Wald A, et al. Stimulant laxatives are effective in chronic constipation: multi-center, 4-week, double-blind, randomized, placebo-controlled trial of bisacodyl. Gastroenterology 2010;138 (Suppl 1):S228.

32. Miner PB, Nichols T, Silvers DR, et al. The efficacy and safety of prucalopride in patients with chronic constipation. Gastroenterology 1999;116(Suppl):A1043

33. Emmanuel AV, Roy AJ, Nicholls TJ, et al. Prucalopride, a systemic enterokinetic, for the treatment of constipation. Aliment Pharmacol Ther 2002;16:1347-56.

34. Coremans G, Kerstens R, De Pauw M, et al. Prucalopride is effective in patients with severe chronic constipation in whom laxatives fail to provide adequate relief. Digestion 2003;67:82-9.

35. Camilleri M, Kerstens R, Rykx A, et al. A placebo-controlled trial of prucalopride for severe chronic constipation. N Engl J Med 2008:358:2344-54.

36. Quigley EMM, Vandeplassche L, Kerstens R, et al. Clinical trial: the efficacy, impact on quality of life, and safety and tolerability of prucalopride in severe chronic constipation-a 12-week, randomized, double-blind, placebo-controlled study. Aliment Pharmacol Ther 2009;29:315-28.

37. Tack J, Van Outryve $\mathrm{M}$, Beyens $\mathrm{M}$, et al. Prucalopride (Resolor) in the treatment of severe chronic constipation in patients dissatisfied with laxatives. Gut 2009;58:357-65.

38. Muller-Lissner S, Rykx A, Kerstens R, et al. A double-blind, placebo-controlled study of prucalopride in elderly patients with chronic constipation. Neurogastroenterol Motil 2010:22:991-8.

39. Barish CF, Drossman D, Johanson JF, et al. Efficacy and safety of lubiprostone in patients with chronic constipation. Dig Dis Sci 2010;55:1090-7.

40. Johanson JF, Ueno R. Lubiprostone, a locally acting chloride channel activator, in adult patients with chronic constipation: a double-blind, placebo-controlled, dose-ranging study to evaluate efficacy and safety. Aliment Pharmacol Ther 2007;25:1351-61. 
41. Johanson JF, Morton D, Geene J, et al. Multicenter, 4-week, double-blind, randomized, placebo-controlled trial of lubiprostone, a locally-acting type-2 chloride channel activator, in patients with chronic constipation. Am J Gastroenterol 2008;103:170-7.

42. Lembo AJ, Kurtz CB, MacDougall JE, et al. Efficacy of linaclotide for patients with chronic constipation. Gastroenterology 2010;138:886-95.

43. Lembo AJ, Schneier H, Lavins BJ, et al. Efficacy and safety of once daily linaclotide administered orally for 12-weeks in patients with chronic constipation: results from 2 randomized, double-blind, placebo-controlled phase 3 trials. Gastroenterology 2010;138(Suppl 1):S53-4.

44. Jones MP, Talley NJ, Nuyts G, et al. Lack of objective evidence of efficacy of laxatives in chronic constipation. Dig Dis Sci 2002;47:2222-30.

45. Tramonte SM, Brand MB, Mulrow CD, et al. The treatment of chronic constipation in adults: a systematic review. J Gen Intern Med 1999;12:15-24.

46. Belsey JD, Geraint M, Dixon TA. Systematic review and meta-analysis: polyethylene glycol in adults with non-organic constipation. Int J Clin Pract 2010;64:944-55.

47. Freedman MD, Schwartz HJ, Roby R, et al. Tolerance and efficacy of polyethylene glycol 3350/electrolyte solution versus lactulose in relieving opiate induced constipation: a double-blinded placebo-controlled trial. J Clin Pharmacol 1997; 37:904-7
48. DiPalma JA, Cleveland MB, McGowan J, et al. A comparison of polyethylene glycol laxative and placebo for relief of constipation from constipating medications South Med J 2007;100:1085-90.

49. Di Palma JA, MacRae DH, Reichelderfer $\mathrm{M}$, et al. Braintree polyethylene glycol (PEG) laxative for ambulatory and long-term care facility constipation patients: report of a randomized, cross-over trial. Online J Dig Health 1999:1:1-7.

50. Cleveland MV, Flavin DP, Ruben RA, et al. New polyethylene glycol laxative for treatment of constipation in adults: a randomized, double-blind, placebo-controlled study. South Med J 2001:94:478-81.

51. Andorsky RI, Goldner F. Colonic lavage solution (polyethylene glycol electrolyte lavage solution) as a treatment for chronic constipation: A double-blind, placebo-controlled study. Am J Gastroenterol 1990:85:261-5.

52. Camilleri M, Van Outryve MJ, Beyens M, et al. Clinical trial: The efficacy of open-label prucalopride treatment in patients with chronic constipation-follow-up of patients from the pivotal studies. Aliment Pharmacol Ther 2010;32:1113-23.

53. Goldberg M, Li Y-P, Johanson JF, et al. Clinical trial: The efficacy and tolerability of velusetrag, a selective $5-\mathrm{HT}_{4}$ agonist with high intrinsic activity, in chronic idiopathic constipation - a 4-week, randomized, double-blind, placebo-controlled dose-response study. Aliment Pharmacol Ther 2010;32:1102-12.

\section{Editor's quiz: GI snapshot}

\section{Perplexing plain abdominal x-ray}

\section{CLINICAL PRESENTATION}

A 62-year-old man presented with generalised abdominal pain of $4 \mathrm{~h}$ duration with associated cough and pyrexia for 2 days. He had developed nephrotic syndrome 17 years previously due to focal segmental glomerulosclerosis and progressed to end-stage kidney disease for which he required haemodialysis three times a week for 6 years. The patient had undergone resection of $10 \mathrm{~cm}$ of his distal small bowel due to obstruction secondary to a benign stricture 5 years previously. Oesophagogastroduodenoscopy, colonoscopy, barium meal and enema studies in the previous 2 years were normal apart from the detection of a small sliding hiatus hernia. Examination revealed diffuse abdominal tenderness without guarding or rebound. There was no palpable organomegaly or mass. The patient's medications included alfacalcidol $0.25 \mu \mathrm{g}$ once per day, sevelamer hydrochloride $800 \mathrm{mg}$ three times per day, lanthanum carbonate $1000 \mathrm{mg}$ three times per day and omeprazole $40 \mathrm{mg}$ once daily as well as medications for hypertension and anxiety. An abdominal x-ray (figure 1a) was performed and compared with an x-ray performed 1 year earlier (figure $1 b$ ).

\section{OUESTION}

What are the major imaging findings on the abdominal x-ray and what is the most likely explanation for these findings? Are these findings relevant to the patient's presentation?

See page 254 for answer

\section{Crush, ${ }^{1}$ O J O'Connor, ${ }^{1}$ W Plant, ${ }^{2}$ M R Clarkson, ${ }^{2}$ F Shanahan, ${ }^{2}$ M M Maher ${ }^{1}$}

${ }^{1}$ Department of Radiology, Cork University Hospital and University College Cork National University of Ireland, Ireland; ${ }^{2}$ Department of Medicine, Cork University Hospital and University College Cork, National University of Ireland, Ireland

Correspondence to Professor Michael M Maher, Department of Radiology, University College Cork, Cork, Ireland; m.maher@ucc.ie

\section{Competing interests None.}

Patient consent Obtained.

Provenance and peer review Not commissioned; externally peer reviewed.

Published Online First 30 August 2010

Gut 2011;60:218. doi:10.1136/gut.2010.215822
Figure 1 Plain x-rays of abdomen performed (a) at presentation and (b) 1 year earlier. Multiple angular hyperdensities are present in the distribution of the colon (a) which were not present following the barium enema (b).
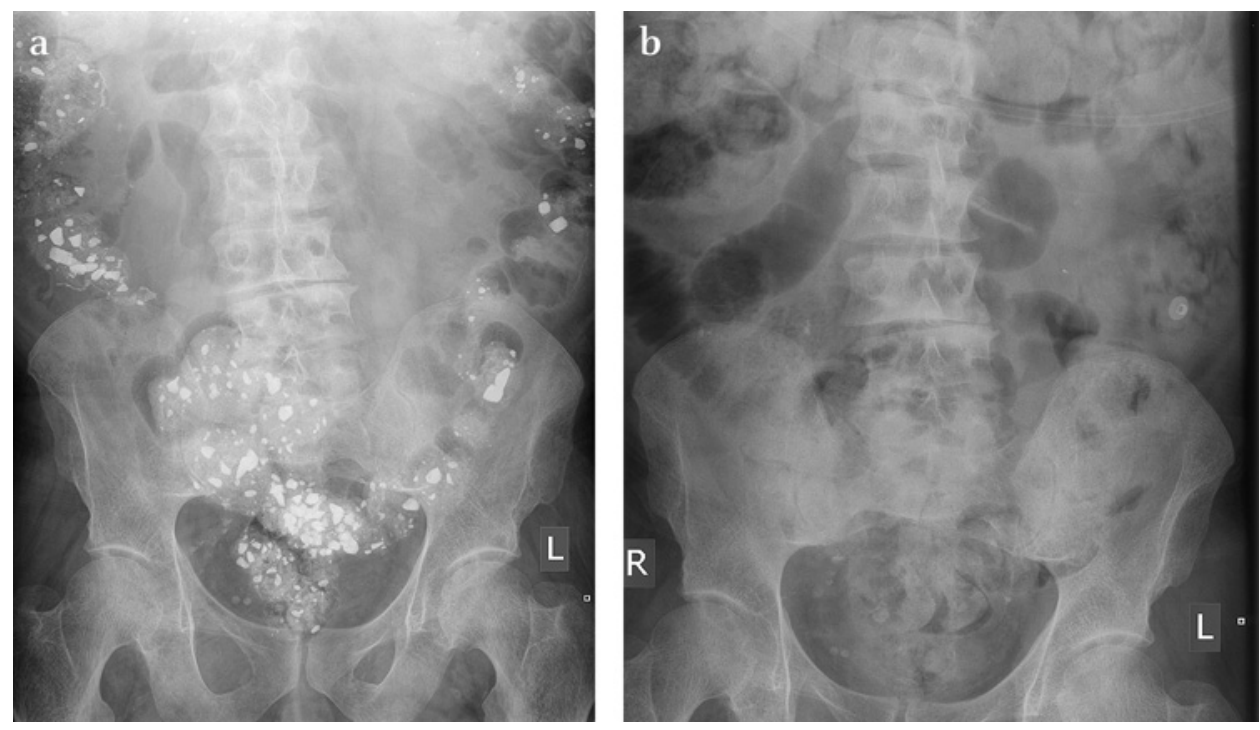